\title{
STRATEGI KESANTUNAN POSITIF DALAM TINDAK TUTUR PADA NOVEL BIDADARI-BIDADARI SURGA KARYA TERE LIYE
}

\author{
Rahmi, Shafruddin Tadjuddin ${ }^{1}$ \\ Pascasarjana Pendidikan Bahasa, Universitas Negeri Jakarta, \\ Jl. Rawamangun muka, Jakarta Timur 13220 \\ Email : rahmi.jkt80@gmail.com
}

\begin{abstract}
This study aims to gain an in-depth understanding of the positive politeness strategy of speech acts in Tere Liye's Bidadari-Bidadari Surga novel. This research is a qualitative research with content analysis method. The data were collected through literature study and polite observation in speech acts on Tere Liye's novel Bidadari-Bidadari Surga. The data analysis uses Brown and Levinson's politeness theory. These findings indicate that Tere Liye's novel Bidadari-Bidadari Heaven contains a positive politeness strategy. The strategy of positive politeness includes fifteen positive politeness strategies and in the form of thirty-nine kinds of mannerisms spoken by the characters of the story.
\end{abstract}

Keywords: Strategy of positive politeness, speech acts, novel

${ }^{1}$ Pembimbing 


\section{PENGANTAR}

Kesantunan merupakan fenomena yang ada dalam masyarakat. Walaupun tidak semua konteks situasi mewajibkan seseorang bertutur santun, (Leech, 2014: 4) namun pelanggaran terhadap kesantunan akan menyebabkan keresahan di dalam masyarakat, seperti yang terjadi pada dua kelompok pemuda di Kabupaten Gowa, Sulawesi Selatan (Sulsel). Sekelompok pemuda marah dan hampir menyerang kelompok pemuda lainnya karena ditertawakan setelah salah satu dari mereka jatuh dari kendaraan roda dua.

Kesantunan merupakan nilai yang penting untuk dikembangkan karena kesantunan berkaitan dengan karakter positif seseorang. Jika seseorang berkomunikasi menggunakan gaya bahasa yang dapat menghaluskan maksud yang ingin disampaikan, maka sifat dan kepribadian seseorang menjadi santun dan halus. Jika seseorang berkomunikasi dengan bahasa yang keras dan kasar, sifat dan kepribadian seseorang itu juga keras dan kasar. (Pranowo, 2009:15).

Hal yang paling diperhatikan dalam kesantunan adalah menjaga wajah orang lain. Yule (2015: 198) menjelaskan kesantunan adalah hal yang berkaitan dengan gagasan seperti penuh pertimbangan, sederhana, dan baik bagi orang lain. Leech 
(2014: 4) menyebut kesopanan dengan istilah altruisme komunikatif. Altruisme adalah tindakan atau perkataan seseorang yang didasari oleh perasaan tidak mementingkan diri sendiri namun demi orang lain. Namun altruisme komunikatif yang berkenaan dengan kesantunan memiliki makna tidak selalu demikian. Maksudnya kadang seseorang bersikap santun karena memang tulus untuk memberikan penghormatan kepada orang lain namun kadang kala kesantunan ditunjukkan untuk kepentingan dirinya sendiri, misalnya untuk mencari pekerjaan, menghindari rasa malu, dsb. Kesantunan menurut Brown dan Levinson (1987: 61) adalah usaha menyelamatkan wajah orang lain.

Tindak tutur yang merupakan rangkaian tindakan yang dilakukan seseorang ketika berbicara, yakni mengucapkan kata-kata (lokusi), menyampaikan maksud di balik kata-kata (ilokusi) dan menimbulkan efek dari kata-kata tersebut kepada mitra tutur (perlokusi), saat ini pembahasannya dikhususkan pada maksud di balik kata-kata (ilokusi). Kesantunan berhubungan dengan penyampaian maksud di balik kata-kata ini. Semakin samarsamar maksud tuturan disampaikan, maka tuturan tersebut semakin santun. (Rahardi, 2005: 165) 


\section{Strategi kesantunan}

positif menurut Brown dan

Levinson (1987:101) adalah

cara bertutur yang dimaksudkan

untuk menyelamatkan wajah

positif orang lain. Wajah positif

adalah keinginan orang lain

untuk dihubungi atau diterima.

Kesantunan positif terkait

dengan sikap bersahabat

dengan orang lain. Seseorang

yang sedang melakukan

kesantunan positif akan

memperlihatkan rasa kesetia-

kawanan serta memperlihatkan

bahwa kedua penutur saling

menghornati satu sama lain.

(Yule, 2014: 111). Ada lima

belas strategi kesantunan

positif, (Brown dan Levinson,

1987) yaitu: a. notice, attend to hearer (his intersest, his wants, his needs, and goods)/memberi perhatian kepada mitra tutur

b. Exaggerate (interst, approval, symphaty with hearer)/ membesar-besarkan ketertarikan kepada mitra tutur

c. intensify interest to hearer/ meningkatkan ketertarikan terhadap mitra tutur.

d. Use in group identity markers/ menggunakan istilah penanda kelompok

e. seek agreement/ mencari kesepakatan.

f. avoid disagreement/ menghindari perselisihan

g. presuppose/raisel assert common geround/ menegaskan adanya kesamaan 
h. joke/menggunakan humor

i. assert or presuppose speaker's knowledge of and concern for hearer's wants/ mengandaikan pengetahuan dan perhatian penutur untuk keinginan mitra tutur

j. offer, promise/ menyatakan janji

k. be optimistic/ menyatakan keoptimisan

1. include speaker and hearer in the activity/ melibatkan mitra tutur

m. give (or ask for) the reason /memberi atau menanyakan alasan

n. assume or assert reciprocity/ menyatakan kerja sama yang timbal bailk

o. give gift to hearer (goods, symphaty, understanding and cooperation)/ memberi

hadiah kepada mitra tutur

Novel adalah karya imajinatif yang mengisahkan sisi utuh atas problematika seseorang atau beberapa orang tokoh. (Kosasih, 2012: 60) Menurut Nurgiyantoro (2013: 417-4118), sebuah teks fiksi umumnya dikembangkan dalam dua bentuk penuturan: narasi dan dialog. Jika dilihat dari penuturan dalam bentuk dialog, percakapan tokoh cerita disajikan dengan teknik langsung dan teknik tidak langsung. Dalam teknik tidak langsung pembaca tidak “mendengar" sendiri kata-kata dan percakapan antara para tokoh sebab percakapan itu telah ditidaklangsungkan oleh 


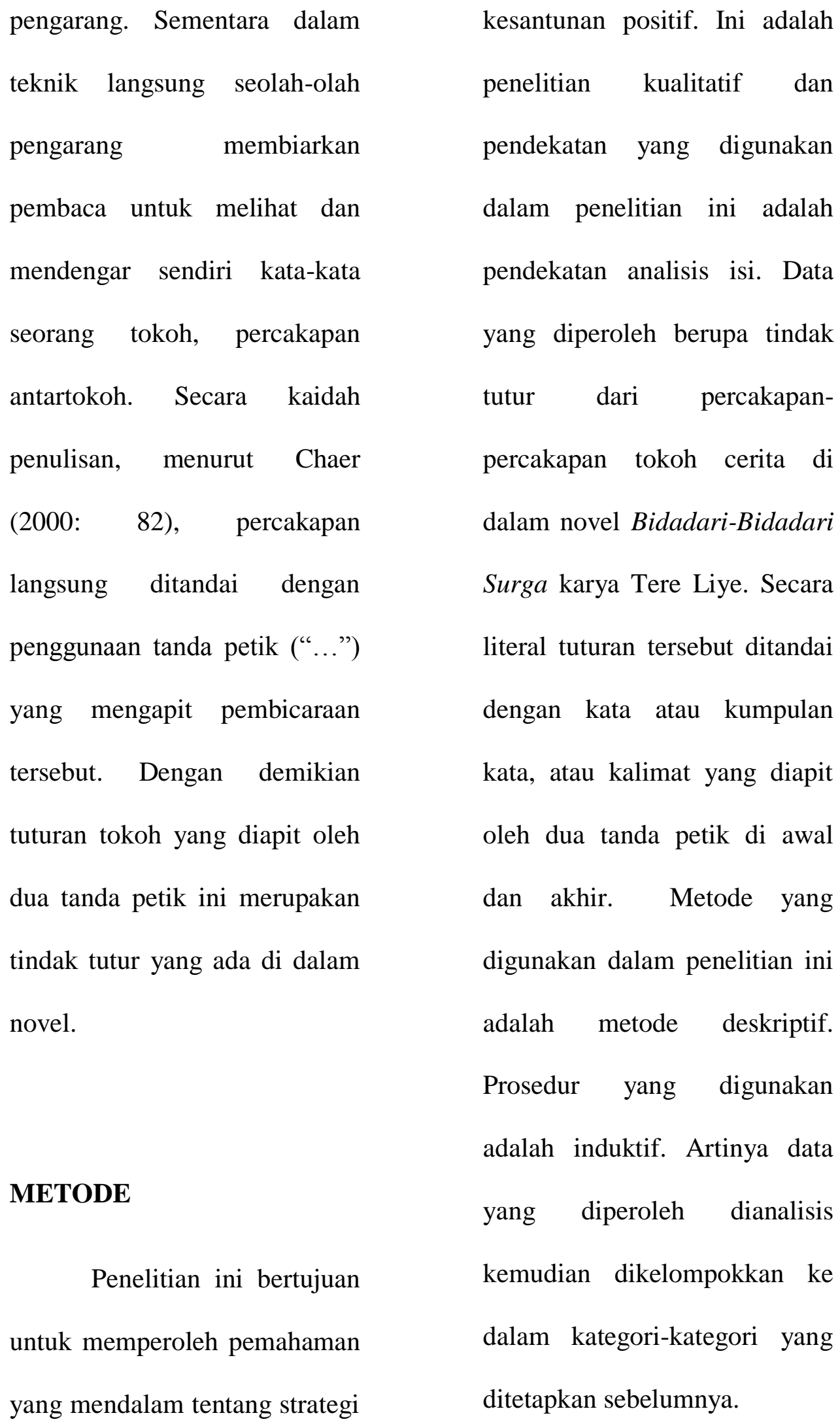


Penilitian ini mengikuti

prosedur penelitian sebagai

berikut: 1) membaca dan

memahami isi cerita dalam

novel Bidadari-Bidadari Surga,

2) mencatat dan mengutip

tindak tutur dalam novel

Bidadari-Bidadari Surga, 3)

melakukan klasifikasi dengan

menggolongkan strategi

kesantunan berdasarkan strategi

kesantunan positif

menafsirkan makna data yang

berkaitan dengan kesantunan

tindak tutur berdasarkan teori

yang digunakan, 5) menarik

kesimpulan dan membuat

rekomendasi, 7)melaporkan

hasil penelitian

\section{HASIL PENELITIAN}

Berdasarkan observasi

terhadap startegi kesantunan positif dalam tindak tutur pada novel Bidadari-Bidadari Surga

karya Tere Liye dapat disimpulkan bahwa novel Bidadari-Bidadari Surga karya Tere Liye mengandung strategi kesantunan positif. Strategi kesantunan positif itu berupa cara bertutur santun yang diucapkan oleh tokoh-tokoh cerita. Cara bertutur santun tersebut adalah:

1) menyebutkan prestasi mitra tutur,

"Hanya soal waktu dia akan membuktikannya. Mengingat profesor muda kita adalah orang pertama di negeri ini yang berkali-kali menulis di jurnal paling pretisius dunia ini. Mendapat pengakuan dari berbagai institusi penelitian dunia, dan selalu konsisten berusaha membuktikan berbagai transkripsi dan 
sejarah religius dari sisi ilmiahnya..."

Konteks: Dituturkan oleh MC kepada Prof. Dalimunte di depan peserta symposium internasional beberapa saat sebelum menyilakan Prof.

Dalimunte mempresentasikan penelitiannya.

2) memuji keluarga mitra tutur,

" Lihatlah, hari ini dia datang dengan isterinya yang terlihat cantik."

Konteks: Dituturkan oleh MC kepada isteri Sang Pembicara Utama simposium internasional itu, Prof. Dalimunte, di depan peserta symposium.

3) menawarkan sesuatu yang dibutuhkan oleh mitra tutur, "Sakit, Kak? Nanti Yashinta kasih minyak urut"

Konteks: Dituturkan oleh Yashinta kepada Kakaknya, Dalimunte, setelah melihat Dalimunte luka-luka karena dipukuli oleh Kak Laisa lantaran ketahuan bolos sekolah.

4) membicarakan hal yang

diminati oleh mitra tutur,

“Anak berang-berangnya

\section{ketemu? Lucu?"}

Konteks: dituturkan oleh Dalimunte kepada adiknya Yashinta yang sedang mengkhawatirkan

keadaannya. Dalimunte membicarakan kegemaran adiknya untuk meredakan kekhawatiran adiknya kepadanya.

5) menggunakan istilah yang lebih dipahami oleh mitra tutur.

" Ingat, disadari atau tidak, ada fakta religius yang tertulis indah di kitab suci:salah seorang sahabat Nabi Sulaiman, maksud saya Solomon buat hadirin yang mengenalnya dengan nama itu."

Konteks: dituturkan oleh Prof.Dalimunte ketika menjadi pembicara di acara symposium internasional. Prof. Dali merasa bahwa tidak semua peserta mengenal Nabi Sulaiman. Oleh karena itu, ia menggunakan nama lain 
dari Nabi Sulaiman agar semua peserta mengerti Nabi Sulaiman yang sedang dibicarakan.

$$
\text { Strategi kesantunan }
$$

positif 2 exaggerate. Strategi ini

dilakukan dengan membesar-

besarkan pujian kepada mitra

tutur. data yang didapat berupa

tutran:

6) penggunaan adverbia yang menyatakan derajat

(kualitas): paling tinggi.

"Penelitian yang amat mengesankan,

mengingat hari ini, ketika kehidupan sudah begitu tidak pedulinya dengan fakta-fakta dalam agama,.."

Konteks: dituturkan oleh MC symposium internasional kepada pembicara utama yang akan mempresentasikan penemuannya.

7) penggunaan interjeksi kekaguman,

" Bukan main, kau hebat Dali! "“

Konteks: dituturkan oleh masyarakat kepada

$\begin{array}{lr}\text { Dalimunte } & \text { karena } \\ \text { idenya } & \text { telah } \\ \text { menghasilkan } & \\ \text { keberhasilan. } & \end{array}$

8) menimbulkan kesan membesar-besarkan pujian

"Baru sehari di sini, tidak pernah kubayangkan, seperti menemukan kembali makna keluarga yang utuh"

Konteks: dituturkan oleh Goughsky kepada keluarga besar Mamak Lainuri karena kebahagiaannya bisa berada di tengah-tengah kehangatan keluarga besar itu.

Strategi kesantunan

positif 3 intensify interest to

hearer dilakukan dengan

meningkatkan ketertarikan

dengan menyuguhkan cerita

kepada mitra tutur kemudian

menyisipkan kata, kalian tahu?

di tengah-tengah cerita yang

sedang disampaikan penutur.

9) “ Keluarga yang hebat meski tidak menyukai publisitas. Masa kecil 
yang penuh perjuangan.. kalian tahu Profesor kita sudah membuat kincir air setinggi lima meter saat ia masih kanak-kanak."

Konteks: dituturkan oleh MC symposium internasional di tengahtengah pengenalan pembicara utama kepada seluruh peserta symposium.

Strategi kesantunan

positif 4 use in group identity dilakukan dengan

menggunakan penanda identitas

kelompok. Data yang diperoleh berupa

10) penggunaan

sapaan

kekerabatan

Bi, kenapa Abi tiba-tiba jadi pendiam?

Konteks: dituturkan oleh Intan, anak berusia 5 tahun, kepada ayahnya, Dalimunte.

11) penggunaan sapaan istimewa

“ Tentu saja my kami baru saja menyetujui salah satu proyek penelitiannya. Seratus ribu dollar. Penelitian yang hebat."

Konteks: dituturkan oleh Ny. Yoko, isteri sang penyokong dana penelitian kepada Yashinta. Mrs. Yoko merasa tidak enak kepada Yashinta karena ia dan suaminya tidak bisa untuk tidak melibatkan Goughsky yang merupakan saingan berat Yashinta dalam proyek penelitian yang akan disokongnya.

12) mengganti kata saya dengan nama sendiri

" Maafkan Dali yang keras kepala..."

Konteks: dituturkan oleh Dalimunte, seorang adik yang sudah menjadi profesor, kepada kakaknya Laisa yang jangankan profesor sekolah pun Laisa tidak.

13) penggunaan bentuk kalimat ellipsis.

" Pulanglah. Sakit kakak kalian semakin parah. Dokter bilang mungkin minggu depan, mungkin besok pagi, boleh jadi pula 
nanti malam. Benar-

benar tak ada waktu

lagi. Anak-anakku, sebelum semuanya terlambat, pulanglah.."

Konteks: dituturkan Mamak Lainuri kepada anak-anaknya karena Laisa, anak pertamanya, sakit keras. Kondisi Laisa saat itu sangat buruk dan hampir mendekati kematiannya namun Mamak Lainuri tidak kuasa mengatakannya secara jelas.

Strategi kesantunan positif 5 seek agreement dilakukan dengan mencari kesepakatan. Data yang diperoleh berupa tuturan yang:

14) mengulang sebagian atau seluruh tuturan mitra tutur.

“ Kau akan segera pulang, Yash. Pagi ini juga. Aku berjanji, paling lambat kita tiba di Lembah Lahambay sebelum siang berakhir."

Konteks: dituturkan oleh Goughsky kepada Yashinta yang sedang terluka parah. Yashinta meminta kepada
Goughsky agar segera mengantarkannya pulang.

15) memberikan persetujuan kepada mitra tutur

"Kau mungkin benar, tidak pantas mendahului Kak Laisa menikah. Tidak pantas. Yash, aku akan tetap menunggu."

Konteks: dituturkan oleh Gougsky kepada Yashinta sebagai pernyataan akan pemahamannya pada kondisi psikologis Yashinta yang tidak mau dilamar olehnya.

16) menggunakan kata ya.

“Ditinggal ya Sayang.. “

Konteks: dituturkan oleh Umi kepada anaknya, Intan yang berusia lima tahun. Umi meminta persetujuan Intan untuk meninggalkan hamster belangnya.

Strategi kesantunan positif 6 avoid disagreement dilakukan dengan menghindari pertentangan. Data yang diperoleh berupa tuturan yang: 
17) mengganti kata-kata yang bermakna kasar, tidak sopan, dsb

"Apakah Kak Lais tidak pernah memikirkan tentang itu saat berdiri sendirian di sini?"

Konteks: dituturkan oleh Dalimunte kepada kakaknya, Laisa. Dalimunte sebenarnya ingin menyebut kata menikah namun karena dikhawatirkan menyinggung perasaan kakaknya, lantaran sampai saat ini kakaknya belum juga menikah, Dalimunte tidak berani. Dalimunte mengganti kata menikah dengan kata itu.

18) menggunakan tanda kesepakatan

“ Baiklah hadirin, berikan sambutan yang paling meriah, inilah salah satu profesor fisika termuda..."

Konteks: dituturkan oleh MC seminar internasional sebagai penanda diakhirinya pengenalannya prihal pembicara utama.

19) mengalihkan pembicaraan
"Kamu sekarang bawa gelang karetnya, Sayang?"

Konteks: dituturkan Dalimunte kepada Intan, anaknya yang berusia lima tahun. Sebelumnya Intan membicarakan prihal penyebab Dalimunte jadi diam. Sebenarnya Dalimunte menjadi diam karena Dalimunte menahan perasaan jengkel kepada Anaknya itu. Dalimunte pun mengalihkan pembicaraan kepada hal yang lebih aman bagi dirinya dan anaknya.

20) mengaburkan pendapatnya sendiri,

"Karena saya pikir kalian sedikit mulai tak sabaran mendengar perkenalan yang sebenarnya amat penting dari saya,..”

Konteks: Dituturkan oleh MC kapada peserta symposium

internasional yang mulai merasa bosan lantaran penyaji memberikan perkenalan yang terlalu panjang tentang pembicara utama symposium itu.

21) berbohong demi kebaikan. 
"Sebenarnya... sebenarnya, Dali juga tidak senang sekolah. Sungguh. Kakak tahu, Dali bahkan lebih suka bekerja di kebun, membantu mamak, membantu kakak.

Konteks: dituturkan oleh Dalimunte kepada kakaknya Laisa karena melihat Laisa sangat sedih dan merasa sangat bersalah karena kegagalan panen itu menyebabkan Dali tidak bisa melanjutkan sekolah. Dali sengaja berbohong dan mengatakan bahwa ia tidak senang sekolah agar Sang Kakak tidak terlalu merasa bersalah kepadanya.

Strategi kesantunan

positif

presuppose/raise/assert

common ground dilakukan

dengan menegaskan adanya

kesamaan antara penutur dan

mitra tutur. data yang didapat

berupa tuturan :

22) membicarakan hal ringan sebelum penutur membicarakan inti

permasalahan

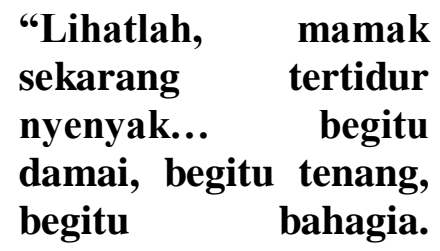

Karena mamak sudah amat bahagia dengan hidupnya. Memiliki kalian, sebagai anakanaknya, adalah kebahagiaan terbesar yang pernah dibayangkan oleh Mamak. Ikanuri dan wibisana, kalian tidak seharusnya menunggu kakak."

Konteks: dituturkan oleh Laisa kepada kedua adiknya, Ikanuri dan Wibisana. Maksud tuturan itu sebenarnya mendesak Ikanuri dan Wibisana untuk segera menikahi pasanganna masing-masing namun karena menjunjung etika, Laisa tidak langsung kepada inti maksud pembicaraannya, melainkan mebicarakan hal lain terlebih dahulu.

23) menggunakan kalimat interogatif embelen

Lihatlah Intan, meski tadi membuat suster 
ngomel-ngomel, tetap saja wajah imutnya menggemaskan, bukan..."

Konteks: dituturkan oleh Laisa kepada Wibisana. Dalam tuturan tersebut terlihat bahwa Laisa memiliki persamaan penilaian tentang Intan, keponakan mereka.

24) menganggap pengetahuan mitra tutur sama dengannya,

"Seperti yang telah
kalian baca di jurnal
tersebut bulan dibelah
menjadi dua sudah
menjadi fakta religius
ratusan silam."

Konteks: dituturkan oleh Prof. Dalimunte kepada peserta symposium internasional. Tuturan tersebut memperlihatkan

Dalimunte menganggap peserta symposium sudah membaca jurnal yang ia maksud.

25) menimbulkan kesan akrab.

Indonesia, senior? Ah, saya tahu Pulau Bali. Cantik, bukan? Jika sempat, suatu saat saya hendak ke sana, berlibur, menghabiskan masa pensiun...

Konteks: dituturkan oleh petugas tiket kereta api di Italia kepada Ikanuri dan Wibisana. Tuturan tersebut menggambarkan bahwa petugas tiket memberikan keramahan kepada Ikanuri dan Wibisana dengan menceritakan keinginannya mengunjungi Pulau Bali. Tuturan petugas kereta api ini membuat suasana menjadi terlihat akrab dan bersahabat.

Strategi kesantunan positif 8 joke dilakukan dengan menggunakan humor. Data yang diperoleh berupa tuturan:

26) penggunaan kata-kata yang menggelitik,

"Jadi buat peserta yang tidak sempat mengenalnya secara langsung, hari ini setelah enam bulan berusaha menculiknya dari jadwal laboratorium yang tidak masuk akal... 
Konteks: dituturkan MC simosium internasional kepada Prof. Dalimunte. MC menggunakan kata yang menggelitik untuk menggambarkan betapa sulitnya menemukan jadwal kosong Sang Profesor.

27) penggunaan logika terbalik.

" Bagaimana mungkin Mamak sakit? Sakit hati pula? Bukankah selama ini Mamak selalu bahagia, meski kami bandel dan nakal?

Konteks: dituturkan oleh Wibisana kepada Sang Ibu karena perasaan bahagianya melihat Sang Ibu sudah kembali dari rumah sakit dan terlihat sehat.

Strategi kesantunan

positif 9 assert or presuppose

S's knowledge of and concern

for H's wants dilakukan dengan mengandaikan pengetahuan dan perhatian penutur untuk keinginan mitra tutur. Data yang diperoleh berupa tuturan argumentasi penutur agar mitra tutur mengikuti sarannya demi kebaikan mitra tutur. Buat apa kau
memikirkan apa yang
dipikirkan orang atas
pernikahan kau. Buat
apa kau memikiran
apa yang dipikirkan
orang atas kakakmu.
Buat apa kau
memikirkan kekhawatiran, rasa cemas, yang sejatinya mungkin tdak pernah ada. Hanya perasaanperasaan. Lihatlah kakak baik-baik saja."

Konteks: dituturkan oleh Laisa kepada Dalimunte agar Dalimunte berhenti untuk mendengar omongan tetangga tentang dirinya dan segera menikahi Cie Hui, kekasihnya.

Strategi kesantunan positif 10 offer promise dilakukan dengan membuat janji. Data yang didapat berupa tuturan

29) mengunakan kata janji

"Aku berjanji, paling lambat kita tiba di 
$\begin{array}{lr}\text { Lembah } & \text { Lahambay } \\ \text { sebelum } & \text { siang } \\ \text { berakhir." } & \end{array}$

Konteks: dituturkan oleh Goughsky kepada Yahinta yang sedang terluka parah.

30) mengungkapkan rencana kegiatan di masa depan yang wajib dilakukan oleh penutur.

$\begin{array}{lr}\text { “Aku tidak } & \text { akan } \\ \text { membiarkan } & \\ \text { Dalimunte, } & \text { Ikanuri, } \\ \text { Wibisana } & \text { dan } \\ \text { Yashinta } & \text { putus } \\ \text { sekolah } & \text { karena } \\ \text { mengganti tanaman di } \\ \text { kebun, Mak.." }\end{array}$

Konteks: dituturkan Yashinta kepada Mamak agar ibunya mengizinkannya menanam strawberi

Strategi kesantunan positif 11 be optimistic dilakukan dengan memberikan sikap optimis. Data yang didapat berupa tuturan:
31) menggunakan adverbial keniscayaan: pasti, tetap

"Yashinta pasti baikbaik saja. ... semua baik-baik saja."

Konteks: dituturkan oleh Ikanuri kepada kakaknya, Dalimunte dengan maksud agar mereka tidak hilang harapan mengenai kabar Yashinta.

32) menggunakan kata-kata yang mengungkapkan keyakinan akan keberhasilan atau harapan di masa depan.

"Kita bisa
melakukannya. Apa
susahnya membuat
kincir-kincir itu.."

Konteks: dituturkan oleh Laisa kepada masyarakat lembah Lahembay agar mereka tidak meragukan ide adiknya, Dalimunte.

Strategi kesantunan positif 12 include both $S$ and $H$ in the activity dilakukan dengan melibatkan mitra tutur dalam 
kegiatan yang akan dilakukan.

Data yang diperoleh berupa

tuturan yang menggunakan

bentuk persona pertama jamak:

kita.

33) "Ya Allah! Itu jelas-jelas Peregrin varian baru! Jenis baru. Ini, ini berarti Gold lefel untuk bantuan penelitian kita. Thanks God! Akhirnya. Akhirnya seratus ribu dollar Amerika untuk konservasi mereka... ،

Konteks: dituturkan oleh Yashinta kepada teman teman tim penelitiannya ketika mendapatkan objek yang pas untuk penelitian mereka.

Strategi kesantunan

positif 13 give (or sk for) the reason adalah kesantunan yang

dilakukan dengan memberi atau

menanyakan alasan. Data yang

diperoleh berupa tuturan

34) menggunakan kalimat majemuk hubungan penyebaban

$\begin{array}{lr}\text { “Aku } & \text { ingin } \\ \text { melakukannya, karena } \\ \text { justru } & \begin{array}{r}\text { dengan } \\ \text { kita } \\ \text { beginilah } \\ \text { akhirnya }\end{array} \\ \text { berkesempatan } & \\ \text { memiliki uang } & \text { yang } \\ \text { cukup buat } & \text { sekolah } \\ \text { Dali di } & \text { kota } \\ \text { kecamatan } & \text { tahun } \\ \text { depan..." } & \end{array}$

Konteks: dituturkan oleh Laisa kepada Mamak. Laisa berusaha meyakinkan ibunya agar mengizinkannya menanam stawberi.

35) menggunakan kata-kata yang sifatnya melatarbelakangi sikapnya,

"Kalau tidak salah Goughsky kakak kelasmu di Belanda, bukan? Terpisah tiga tahun? Jadi aku pikir dia lebih pantas menjadi leader proyek ini, Sayang"

Konteks: dituturkan oleh Mr. Yoko kepada Yashinta. Mr. Yoko secara tidak langsung menyampaikan

alasannya memilih Goughsky menjadi leader proyek yang akan mereka kerjakan.

36) bertanya. 
"Kak Laisa belum tidur?"

Konteks: dituturkan oleh Dalimunte kepada kakaknya, Laisa karena mendapati Laisa yang belum tidur meski hari telah larut.

Strategi kesantunan

positif 14 assume or assert reciprocity dilakukan dengan menyatakan kerjasama yang timbal balik. "Aku sudah membuat dua kemarin.. sudah ada di sungai bawah cadas."

Konteks: dituturkan oleh Dalimunte kepada masyarakat lembah Lahembay. Tuturan tersebut mengisyaratkan bahwa mereka hanya mengerjakan 3 dari 5 kincir-kincir yang harus mereka kerjakan.

Tuturan

yang

menggunakan

strategi

kesantuna positif 15 Give

sympathy to $H$ dilakukan

dengan memberi hadiah kepada mitra tutur. data yang didapat berupa tuturan:

38) mengucapkan terima kasih

"Terima kasih, Kak"

Konteks: dituturkan

oleh Yashinta kepada

kakaknya, Ikanuri dan

Wibisana karena telah

diberi hadiah berupa

pensil warna.

39) mengucapkan selamat.

\section{"Selamat menikmati}

Eurostar, Senior. Semoga

nyaman.

Konteks: Dituturkan oleh petugas tiket kereta api di Italia kepada Ikanuri dan

Wibisana.

\section{KESIMPULAN}

Novel

Bidadari-

Bidadari Surga karya Tere Liye

mengandung

strategi 
kesantunan positif dalam tindak tutur tokoh ceritanya. Strategi kesantunan positif yang didapat berupa 39 cara bertutur santun, yaitu 1) menyebutkan prestasi mitra tutur, 2) memuji keluarga mitra tutur, 3) menawarkan sesuatu yang dibutuhkan oleh mitra tutur, 4) membicarakan hal yang diminati oleh mitra tutur, 5) menggunakan istilah yang lebih dipahami oleh mitra tutur. 6) penggunaan adverbia yang menyatakan derajat (kualitas): paling tinggi. 7) penggunaan interjeksi kekaguman, 8) menimbulkan kesan membesar-besarkan pujian kepada mitra tutur, 9) meningkatkan ketertarikan dengan menyuguhkan cerita kepada mitra tutur kemudian menyisipkan kata, kalian tahu? di tengah-tengah cerita yang sedang disampaikan penutur, 10) penggunaan sapaan kekerabatan, 11) penggunaan sapaan istimewa, mengganti kata saya dengan namanya sendiri, penggunaan bentuk kalimat ellipsis, 14) mengulang sebagian atau seluruh tuturan mitra tutur, 15) memberikan persetujuan kepada mitra tutur, 16) menggunakan kata ya. 17) mengganti kata-kata yang bermakna kasar, tidak sopan, 18) menggunakan tanda kesepakatan, 19) mengalihkan pembicaraan, 20) mengaburkan pendapat sendiri, berbohong demi kebaikan, 22) membicarakan hal ringan sebelum penutur membicarakan inti permasalahan, 23) 


\begin{tabular}{|c|c|}
\hline menggunakan & menggunakan \\
\hline interogatif embelen, & majemuk \\
\hline menganggap pengetahuan mitra & penyebaban, 35) menggunakan \\
\hline tutur sama dengannya, 25) & kata-kata yang sifatnya \\
\hline menimbulkan kesan akrab. 26) & melatarbelakangi sikapnya, 36) \\
\hline penggunaan kata-kata yang & bertanya, 37) menyatakan \\
\hline menggelitik, 27) penggunaan & kerjasama yang timbal balik, \\
\hline logika $\quad$ terbalik. & 38) mengucapkan terima kasih, \\
\hline menyampaikan argumentasi & 39. mengucapkan selamat. \\
\hline agar mitra tutur mengikuti & \\
\hline sarannya demi kebaikan mitra & UCAPAN TERIMAKASIH \\
\hline tutur. 29) mengunakan kata & melibatkan \\
\hline janji, 30) mengungkapkan & banyak pihak dalam pembuatan \\
\hline rencana kegiatan di masa depan & artikel ini. Oleh karena itu, \\
\hline yang wajib dilakukan oleh & peneliti mengucapkan terima \\
\hline penutur, 31) menggunakan & kasih kepada semua pihak yang \\
\hline adverbial keniscayaan: pasti, & telah memberikan dukungan, \\
\hline tetap, 32) menggunakan kata- & khususnya kepada yth. Dr. \\
\hline kata yang mengungkapkan & Herlina, $\quad$ M. Pd selaku \\
\hline keyakinan akan keberhasilan & pembimbing I yang senantiasa \\
\hline atau harapan di masa depan, & penulis untuk \\
\hline 33) menggunakan bentuk & menyelesaikan penelitian ini. \\
\hline ersona pertama jamak: $k i$ & Yth. Dr. Shafruddin Tadjuddin, \\
\hline
\end{tabular}


M.A selaku pembimbing II atas

kesabarannya memberikan

arahan kepada peneliti. Selain

\section{BIBLIOGRAFI}

itu ucapan terima kasih

ditujukan kepada jajaran

pimpinan Pascasarjana

Universitas Negeri Jakarta,

yaitu yth. Prof. Dr. Moch.

Asmawi,M.Pd., selaku Direktur

Brown, Penelope dan Stephen

C. Levinson. 1987.

Politeness Some

Universal in Language

Usage. New York:

Cambridge University.

Pascasarjana Universitas

Negeri Jakarta. Prof. Dr.

Ma'ruf Akbar, M.Pd. selaku

Wakil Direktur Pascasarjana

Rineka Cipta.

Universitas Negeri Jakarta. Dr.

Ninuk Lustyantie, M.Pd. selaku

Koordinator $\quad$ S2 $\quad$ Prodi

Pendidikan Bahasa yang telah

memberikan saran kepada

peneliti. Peneliti juga

Liputan

6.

mengucapkan terima kasih

http://regional.liputan6.

kepada Jurnal Bahtera yang

com/read/2982334/kisa

telah membantu peneliti

h-konyol-pemuda-

mempublish penelitian ini.

tanggung-hampir-sulut- 
tawuran-antar-kampung

(Diunduh tanggal 10 Juni 2017)

Kosasih, E. 2012. Dasar-Dasar

Keterampilan

Bersastra. Bandung:

Yrama dan Jurusan

Pendidikan Bahasa dan

Sastra Indonesia UPI

Nurgiyantoro, Burhan. 2013.

Teori Pengkajian Fiksi.

Yogyakarta: Gadjah

Mada University Press.
Pranowo. 2009. Berbahasa

secara Santun. Yogyakarta:

Pustaka Pelajar.

Rahardi, Kunjana. 2005.

Kesantunan Imperatif

Bahasa Indonesia.

Jakarta: Erlangga.

Yule, George. 2014. Pragmatik.

Yogyakarta: Pustaka Pelajar.

2015. Kajian

Bahasa Edisi

Kelima.Yogyakarta:

Pustaka Pelajar 